\title{
Relationships between some psychological assessments, body-build, and physiological stress responses
}

\author{
P. K. BRIDGES AND M. T. JONES \\ From the Regional Neurosurgical Centre, Brook General Hospital, Shooters Hill Road, \\ and
} Sherrington School of Physiology, St. Thomas's Hospital, London

SUMMARY A number of physiological responses to the psychological stress of an oral academic examination were observed, including heart rate, respiration rate, blood pressure, urinary 17oxogenic steroid excretion, and plasma corticosteroid concentration. The results were related to body-build and to four psychological tests: Eysenck Personality Inventory, Taylor Manifest Anxiety Scale, IPAT Anxiety Scale, and Stimulus-Response Inventory. No significant associations were found between the psychological test results and anticipatory physiological activity just before the examination began, including excretion of 17-oxogenic steroids. Respiration rate was not increased by anticipatory stress, unlike the other variables, which were significantly higher than control values taken under resting conditions three months later. The students of primarily linear physique had significantly higher plasma corticosteroid values than the predominantly muscular subjects at the time of the examination, as found previously. They also had significantly higher analogue measures of the degree of anxiety experienced at the examination (assessed both by the subject and by an observer). Therefore, linear subjects appear to experience more anxiety than muscular students in a similar situation of psychological stress. Both the IPAT Scale and S-R Inventory results were significantly higher for the linear group but there were no significant differences for the EPI and TMAS scores, as used in previous studies. The importance of constitutional factors associated with body-build in relation to at least some aspects of personality is strongly suggested by the findings.

We have previously described investigations into possible relationships between constitutional factors and some physiological responses to a psychological stress. For example, it was shown that plasma corticosteroid concentrations produced by the stress were significantly related to body-build but not to the results obtained from some personality tests (Bridges and Jones, 1968). However, it must be expected that the results from suitable psychological tests, if they have validity, should predict those subjects experiencing relatively more anxiety in stressful situations and thus relationships with the physiological responses are to be anticipated. This was not found to be so for the Eysenck Personality Inventory (EPI) (Eysenck and Eysenck, 1964) or for the Taylor Manifest Anxiety Scale (TMAS)
(Taylor, 1953) used in previous studies. But it remained possible that other personality measures designed for anxiety-proneness might prove more relevant to the experimental situation and show relationships with the physiological parameters. Therefore, further psychological tests were given to another group of students in a similar situation as before.

In the present study the opportunity was also taken to observe possible differential associations between responses to anticipatory anxiety, occurring before the examination, and those due to the anxiety produced during the period of the examination itself. This report considers the relationships between the various physiological measures, their associations with body-build and with some of the psychological test results. 


\section{METHODS}

The study was restricted, as in previous investigations, to male students at one medical school, all aged about 20 years. All 46 taking the second MB anatomy oral examination on one occasion agreed to take part but the data were complete only for $\mathbf{4 2}$.

Shortly before the examination was due to begin each student voided urine, which was discarded. While waiting to enter the examination the student sat quietly and immediately before it began the first observer counted the heart rate and respiration rate, each over one minute, and the blood pressure was taken. It was noted that the respiration rate was affected if the subject became aware of it being recorded so the wrist was palpated with apparent concentration on this by the observer while counting both the pulse and respiration rates. Each examination lasted between 10 and 20 minutes and immediately at its conclusion the heart rate, respiration rate, and blood pressure were again recorded. It had previously been found that these variables decelerated or fell rapidly as soon as the stress was over, so second and third observers were available. The second took the heart rate over 30 seconds and the respiration rate over 30 seconds, while the third observer recorded the blood pressure at the same time.

Each student then drank $250 \mathrm{ml}$. water to facilitate diuresis and sat quietly until 30 minutes after the start of the examination when $10 \mathrm{ml}$. blood was collected into a tube with heparin. This was immediately centrifuged and the plasma stored deep frozen for later assay of corticosteroids. Haematocrit readings were carried out in duplicate. The subject continued resting until one hour after the commencement of the examination when the bladder was emptied and the urine stored deep frozen for later measurement of 17-oxogenic steroids. The weight of each student was taken at the time of the examination.

While it would have been desirable, it was not possible to insist that the subjects refrain from smoking or drinking caffeine beverages before the examination, although this would not be allowed during the period after the examination while the specimens were collected. However, each student was asked about his recent smoking habits and also whether there had been vomiting or diarrhoea in the fortnight before the examination.

Three months after the examination, control observations were obtained. An attempt was made to carry these out as near as possible to the same time of day at which the examination was taken in order to avoid effects resulting from diurnal variation in physiological activity. The mean difference between the time of day at which the stress and control readings were recorded for each student proved toథ be -2.64 minutes ( $S D \pm 109.9$ minutes).

The control period began with the subject voidin 9 urine, which was discarded; each then drank $250 \mathrm{ml}$ water and rested. The blood specimen was takem 30 minutes later for measurement of plasma cortico@ steroids and one hour later urine was collected fo assay of 17-oxogenic steroids. Physical measurement $\overrightarrow{2}$ were then recorded for the purpose of assessing the phenotype by the method of Parnell (1958) and the psychological test forms were completed. These in? cluded the EPI, TMAS, IPAT Anxiety Scale (Cattel and Scheier, 1963) and the Stimulus-Response (S-R Inventory (Endler, Hunt and Rosenstein, 1962). The latter is a complicated test with many subscores buy only the total scores are considered here. A more detailed analysis of the results from the psychologicaP tests will be reported separately (Bridges, 1973).

A visual linear analogue scale (Aitken, 1969) was? also used to assess the degree of anxiety experienced during the examination and to quantify any anxiet: felt during the collection of control data. The ob? servers, in taking previous stress recordings, wबir aware of perceiving the degree of disturbance eatks student appeared to show. It was not known hợ reliable these assessments were, so it was decipe that, while no structuring of the opinion was attermpo ted, the second observer would make a similar ana logue measurement of the state of each studer? anxiety as it appeared immediately after the examina tion. Each analogue scale was $100 \mathrm{~mm}$ long with $\overrightarrow{\mathrm{g}} \overrightarrow{\mathrm{no}}$ indication of 'no anxiety' at one end and 'the mostw anxiety you can imagine' at the other, a mark alonge the line being the assessment of the degree of anxiety These scales were marked by each student and by the second observer at the time of the stress and bo the student only on the occasion of the collection of control data, when some anxiety was possible, especi ally due to the venepuncture involved.

In our previous studies corticosteroids were as sayed by a modification of the method of Zenket and Bernstein (1958). More specific methods are now. available and therefore the method of Townsend and James (1968) was used for all blood samples, contro? and stress, while the stress samples were also meas 3 ured by the modified Zenker and Bernstein methoc for comparison. Urinary 17-oxogenic steroids weres measured by the method of Gray, Baron, Brooks and James (1969).

\section{RESULTS}

Tables 1 and 2 show that, using $t$ tests of differis ences, all the physiological measures were signifio cantly higher at the time of the stress compare 
TABLE 1

PHYSICAL, URINARY AND ADRENOCORTICAL MEASURES (MEAN VALUES)

\begin{tabular}{|c|c|c|c|c|c|c|c|c|c|c|c|}
\hline & \multicolumn{2}{|c|}{$\begin{array}{l}\text { Weight } \\
(k g)\end{array}$} & \multirow{3}{*}{$\begin{array}{c}\text { Haema- } \\
\text { tocrit } \\
(\%)\end{array}$} & \multicolumn{3}{|c|}{$\begin{array}{l}\text { Plasma corticosteroids } \\
\quad(\mu \mathrm{g} \text { per } 100 \mathrm{ml} .)\end{array}$} & \multicolumn{2}{|c|}{$\begin{array}{c}\text { 17-Oxogenic } \\
\text { steroids } \\
(\mu \mathrm{g} / \mathrm{hr})\end{array}$} & \multicolumn{3}{|c|}{$\begin{array}{l}\text { Urine flow } \\
(\mathrm{ml} / \mathrm{|hr})\end{array}$} \\
\hline & \multirow[b]{2}{*}{ Con. } & \multirow[b]{2}{*}{ Stress } & & \multicolumn{2}{|c|}{$\begin{array}{l}\text { Townsend and } \\
\text { James method }\end{array}$} & \multirow{2}{*}{$\begin{array}{c}\text { Zenker and } \\
\text { Bernstein } \\
\text { method } \\
\text { Stress }\end{array}$} & \multirow[b]{2}{*}{ Con. } & \multirow[b]{2}{*}{ Stress } & \multirow[b]{2}{*}{ Con. } & \multirow[b]{2}{*}{ Stress } & \multirow[b]{2}{*}{$\%$ decrease } \\
\hline & & & & Con. & Stress & & & & & & \\
\hline $\begin{array}{l}L \text { group }(n=13) \\
M \text { group }(n=23)\end{array}$ & $\begin{array}{l}66 \cdot 50 \\
71 \cdot 57\end{array}$ & $\begin{array}{l}67 \cdot 77 \\
72 \cdot 00\end{array}$ & $\begin{array}{l}45 \cdot 62 \\
45 \cdot 61\end{array}$ & $\begin{array}{l}8 \cdot 46 \\
7 \cdot 96\end{array}$ & $\begin{array}{l}18 \cdot 23 \\
13 \cdot 74\end{array}$ & $\begin{array}{l}35 \cdot 19 \\
30 \cdot 77\end{array}$ & $\begin{array}{l}541 \\
451\end{array}$ & $\begin{array}{l}761 \\
586\end{array}$ & $\begin{array}{r}116 \cdot 92 \\
98 \cdot 87\end{array}$ & $\begin{array}{l}87 \cdot 38 \\
60 \cdot 17\end{array}$ & $\begin{array}{l}74 \cdot 7 \\
60 \cdot 9\end{array}$ \\
\hline$P(L$ v. $M)$ & NS & NS & NS & NS & $<0.01$ & $<0.05$ & NS & NS & NS & NS & - \\
\hline $\begin{array}{l}\text { All subjects }(n=42) \\
P \text { (control v. stress) }\end{array}$ & $70 \cdot 54$ & $\begin{array}{l}71 \cdot 14 \\
S\end{array}$ & $45 \cdot 50$ & $8 \cdot 17<$ & $15 \cdot 12$ & $31 \cdot 80$ & $\begin{array}{r}464 \\
<\end{array}$ & 093 & $\begin{array}{r}97 \cdot 57 \\
<C\end{array}$ & $\begin{array}{l}66 \cdot 07 \\
.02\end{array}$ & $67 \cdot 72$ \\
\hline
\end{tabular}

TABLE 2

RESPIRATORY AND CARDIOVASCULAR MEASURES (MEAN VALUES)

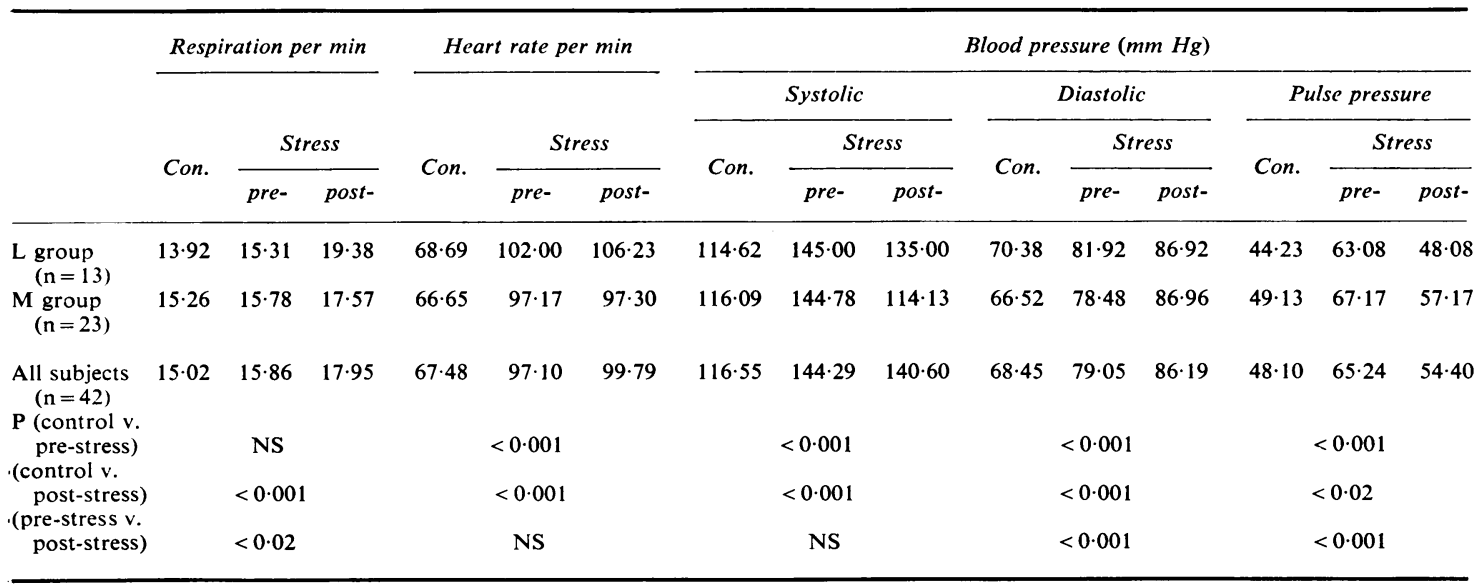

TABLE 3

PSYCHOLOGICAL MEASURES (MEAN VALUES)

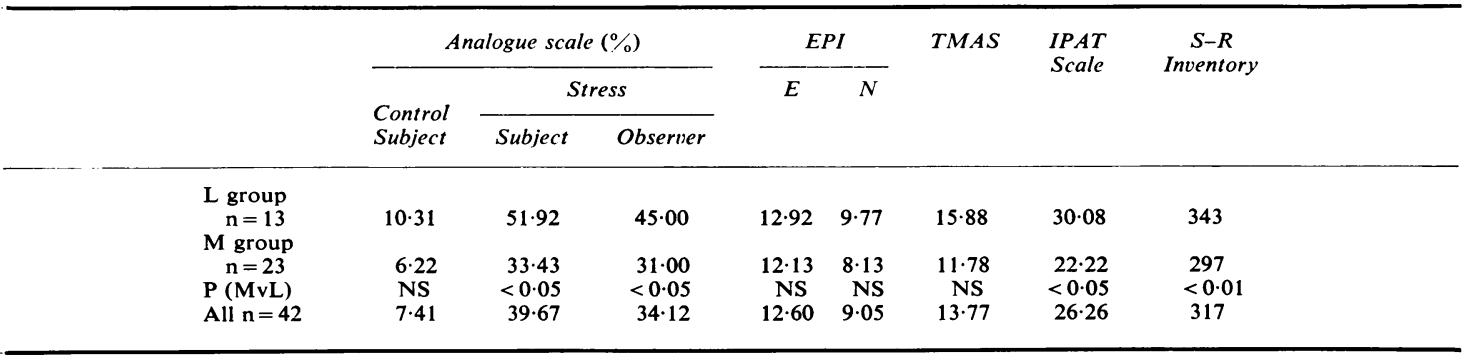


with control values, except that urine flow was significantly reduced.

The phenotype is a measure of body-build expressed in terms of three components; linearity or thinness (L), muscularity (M), and fatness (F). Subjects were grouped into those with each component predominant. Therefore, the results were calculated to give separate mean values for those of primarily linear physique $(\mathrm{L}, \mathrm{Lm}, \mathrm{Lf}: \mathrm{n}=13$ ) and also for the predominantly muscular students $(\mathrm{M}, \mathrm{Mf}, \mathrm{Ml}: \mathrm{n}=23)$. Six subjects remained outside these categories, of whom two were primarily fat (both Fm) and four showed equal main components $(2=\mathrm{FL}, 2=\mathrm{ML})$. The low incidence of primary fatness among university students has been noted before (Bridges and Jones, 1968).

PSYCHOLOGICAL TESTS Table 3 gives the mean results of the psychological tests for the total group of students and also for each of the two main phenotype groups. The subjects' analogue assessments for all the students were highly significantly increased at the time of the stress compared with the control values, using a $t$ test of differences $(t=8.84, \mathrm{P}<0.001)$. The mean stress analogue assessments, both subjects' and observer's, were significantly higher for the linear group than for the primarily muscular subjects. All the psychological measures produced a higher mean value for the linear subjects than the muscular group but the differences were significant only in the case of the IPAT scale and the S-R Inventory. It is noteworthy that the observer and subject analogue ratings carried out at the time of the examination correlated significantly together $(r=0.4203 ; P=<0.01)$.
None of the three analogue assessments showed significant correlations with the otheif psychological tests, except that between the subjects' stress analogue ratings and the $\mathrm{S}-\mathrm{R}$ Inventory $(r=0.3721 ; P<0.05)$. As reported by several other workers (Jensen, 1958), using thi closely related Maudsley Personality Inventory the neuroticism $(\mathrm{N})$ score of the EPI correlated highly significantly with the TMAS $(r=0.8892$ $P<0.001)$. In addition, the IPAT scale results correlated significantly both with the $\mathrm{N}$ scores of the EPI $(r=0.7417 ; P<0.001)$, and the TMAS $(\mathrm{r}=0.7680 ; \mathrm{P}<0.001)$. The total $\mathrm{S}-\overline{\mathrm{B}}$ values also correlated significantly with the scores $(r=0.6449 ; P<0.001)$, the TMAS $(r=$ $0.6355 ; \mathrm{P}<0.001)$ and the IPAT values $(\mathrm{r} \stackrel{=}{=}$ $0.6433 ; \mathrm{P}<0.001$ ).

ADRENOCORTICAL RESPONSES The only signif cant differences found between the two phen $\dot{\sigma}_{-}$ type groups for the physiological variables curred in the plasma corticosteroid values at thes time of the stress. Measured by both method\$ assay, the linear group had significantly higher mean values compared with the muscular sitbo jects, while the control values were closely simp: lar. The linear subjects also showed higher mea excretion rates of 17-oxogenic steroids in both control and stress conditions, but the differenees were not significant. The 17-oxogenic steroid excretion values at the time of the stress correo lated significantly with the control figures $(\mathrm{r}=$ $0.3988 ; \mathrm{P}<0.01$ ), but this was not so of the plasma corticosteroid results, and there were ne significant relationships between the urinary an\& plasma steroid results.

Significant correlations were found betweeñ

TABLE 4

SUMMARY OF PRINCIPAL INTERCORRELATIONS

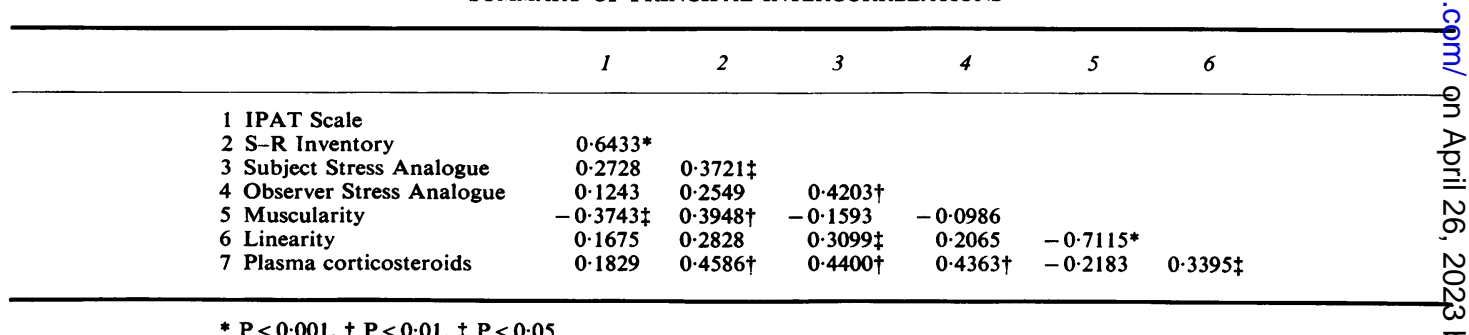

$* \mathrm{P}<0.001 .+\mathrm{P}<0.01 . \ddagger \mathrm{P}<0.05$ 
the stress plasma corticosteroid values and three of the psychological measures (S-R Inventory, observer's and subjects' stress analogue ratings), as shown in Table 4. The stress plasma corticosteroid values measured by the two different methods correlated together highly significantly $(\mathrm{r}=0.6035 ; \mathrm{P}<0.001)$ and therefore the plasma corticosteroid results are generally comparable with those in our previous studies. The correlation coefficient between the linear phenotype scores and the stress corticosteroid values measured by the Townsend and James method was $0.3395(\mathrm{P}<0.05)$, while that between the latter and the muscularity ratings was -0.2183 (NS).

OTHER PHYSIOLOGICAL MEASURES A previous finding (Jones, Bridges, and Leak, 1968) is confirmed that urine flow decreases significantly in response to a psychological stress. The decrease is greater for subjects of linear build than for primarily muscular individuals, although these differences did not reach significance. The results for other variables are given in Table 2, from which it is apparent that there are no significant differences between the mean values for the two phenotype groups.

PERSONAL VARIABLES It had been considered possible that anticipatory anxiety over a period of time before the examination might have led to general metabolic changes which could influence the results. The haematocrit values were taken as an indication of hydration and these were all normal. Weight was not found to be significantly different at the time of the examination compared with control values. There were no significant differences in the reported incidence of smoking, of diarrhoea, and of vomiting between the phenotype groups.

In view of the significant relationships found between plasma corticosteroid values and phenotype ratings, as well as with some of the psychological tests, it is to be expected that the phenotype values would correlate significantly with some of the personality measures and this was so as shown in Table 4.

\section{DISCUSSION}

The pre-stress recordings were considered to be a possible indication of anticipatory anxiety, as opposed to the post-stress values which were more directly produced by the examination. In the present study the urinary steroid values were intended as a possible measure of anticipatory stress occurring in the period before the examination, while the plasma values were regarded as an assessment of the emotional stimulus produced by the examination and thus urinary oxogenic steroid excretion was not included for direct comparison with the plasma corticosteroid values. The latter is a more immediate assessment of adrenocortical activity and it is also an assessment at a single point of time, reflecting events about 30 minutes before. The delay between stimulus and increased urinary steroid excretion is a good deal longer and depends upon various factors such as the magnitude of the stimulus and the method of assay, but the interval will be more like three hours (Doe, Vennes, and Flink, 1960). It appears that anticipatory anxiety, as measured by urinary steroid output, produces values which are significantly increased over control figures. But this particular measure of anticipation does not show relationships with the stress responses occasioned by the examination, as measured by plasma corticosteroid concentration and other aspects of physiological activity. Furthermore, none of the psychological tests significantly correlated with the stress 17-oxogenic steroid values and therefore no relationships were found to differentiate psychological factors associated with anticipatory physiological activity from those associated with the stress responses.

However, it is clear that respiration rate was not affected by anticipatory anxiety, as the mean rate increased significantly over control values only after the stress. This finding probably relates to the fact that respiration is not controlled by the autonomic nervous system and it obviously was not involved in the increased autonomic activity before the examination. It may be that its acceleration was more directly related to arousal produced by the examination itself.

By contrast, all the cardiovascular variables taken before the stress were increased significantly over control values. Heart rate and systolic blood pressure did not significantly increase further after the examination, compared with the results taken just before it began. But this was not so of diastolic blood pressure, which was 
found to be even higher at the end of the examination. This could be explained in terms of increased sympathetic tone but observer error cannot be excluded as the pre-stress values were taken by the first observer, while the later recordings were carried out by the third observer.

Adrenocortical activity is known to be related both to parameters of body size (Borth, Linder, and Riondel, 1957; Tanner, Healey, Whitehouse, and Edgson, 1959) and to psychological arousal (Martin, 1961 ; Levi, 1969). Rose, Poe, and Mason (1968) and Poe, Rose, and Mason (1970) found that the combined use of assessments of psychological state and of body build gave the best predictions of 17-hydroxycorticosteroid excretion rates during various activities carried out by military recruits under training. Segraves (1970) did not study stress responses but found relationships between resting steroid excretion, measures of personality, and parameters of bodybuild. The results of our previous studies went somewhat further in suggesting a positive relationship between linearity and plasma steroid levels, and a negative association with muscularity, indications being that the latter is the more important (Bridges, Jones, and Leak, 1970) but it is difficult to decide this point as muscularity and linearity in any case have a highly significant negative relationship (in the present study $\mathrm{r}=-0.7115 ; \mathrm{P}<0.001)$. With our several previous investigations, as well as the present findings, there are now 122 subjects for whom plasma corticosteroid results have been obtained in similar stress conditions. In the case of these 122 subjects the correlations between their plasma corticosteroid values (Zenker and Bernstein method) and linearity was $0.2173(\mathrm{P}<0.05)$; with muscularity it was $-0.2007(\mathrm{P}<0.05)$.

One explanation of the differences in stress corticosteroid values between subjects of different phenotype groups might be a variation in the sensitivity of adrenocortical responsiveness but it has been shown that the response of the adrenal cortex of both phenotype groups to tetracosactrin is closely similar (Jones and Bridges, 1970). Among other explanations of the differences is the likelihood that linear subjects tend to experience relatively more anxiety under stress than do muscular individuals. This was previously suggested by some observations reported by Parnell (1957) and there is now evi- dence from the present analogue assessmentso that the linear students experienced significantly higher levels of anxiety than the muscular sub jects, assessed both by themselves and by aff observer. These findings also confirm the obseren vation of Bloch and Brackenridge (1972) that self-ratings of anxiety can be employed with confidence in research of this kind.

Having established that there are difference $\vec{F}$ in the physiological responses between phenotype groups under a similar stress, it is of interest tof note the psychological tests which relate to these differences. It is apparent that the EPI and TMAS do not, while the IPAT and the S-Ro Inventory appear to do so, an aspect considered. further in the separate study (Bridges, 1973) These tests are all relevant to anxiety-proneness and the latter two appear to measure this with? some reliability, even to the extent, in the case of the S-R Inventory, that scores obtained threet. months later correlated significantly with stress plasma corticosteroid values and also with tige subjects' analogue assessments of the anxidy experienced. Thus, while our previous studes have shown significantly different physiologiç 5 stress response patterns between subjects different body-builds, evidence is now availa which more clearly suggests that these phystological differences are related to psychologicak differences in anxiety responsiveness between phenotype groups. This demonstration thaf anxiety responses relate to body-build and, probably as an aspect of this, that certain psychological tests correlate with body-build, has rele vance to frequently suggested associations be $\frac{\Omega}{2}$ tween physique and temperament (Sheldon, $\overrightarrow{\overrightarrow{0}}$ 1942; Rees, 1960).

For advice and help with this study we thank Profes sor V. H. T. James, Professor P. Venables, Dr. R. V Brooks, Dr. F. Imms, Mr. R. Neame, Mr. M. Piercyo and the medical students of St. Thomas' HospitaS Medical School. The support of the Royal Free. Hospital Endowment Fund and the South Ease Metropolitan Regional Hospital Board is gratefully acknowledged.

\section{REFERENCES}

Aitken, R. C. B. (1969). Measurement of feelings using visuaf analogue scales. Proceedings of the Royal Society of Medicine, 62, 989-993.

Bloch, S., and Brackenridge, C. J. (1972). PsychologicalN performance and biochemical factors in medical students 
under examination stress. Journal of Psychosomatic Research, 16, 25-33.

Borth, R., Linder, A., and Riondel, A. (1957). Urinary excretion of 17 -hydroxycorticosteroids and 17-ketosteroids in healthy subjects, in relation to sex, age, body weight and height. Acta Endocrinologica, 25, 33-44.

Bridges, P. K. (1973). Practical aspects of the use of some psychological tests of anxiety in a situation of stress. British Journal of Psychiatry. (In press.)

Bridges, P. K., and Jones, M. T. (1968). Relationship of personality and physique to plasma cortisol levels in response to anxiety. Journal of Neurology, Neurosurgery, and Psychiatry, 31, 57-60.

Bridges, P. K., Jones, M. T., and Leak, D. (1970). A taxonomic study of physiological responses to a psychological stress. Journal of Neurology, Neurosurgery, and Psychiatry, 33, 180-187.

Cattell, R. B., and Scheier, I. H. (1963). Handbook for the I.P.A.T. Anxiety Scale Questionnaire. Institute for Personality and Ability Testing: Colorado.

Doe, R. P., Vennes, J. A., and Flink, E. B. (1960). Diurnal variation of 17-hydroxycorticosteroids, sodium, potassium, magnesium and creatinine in normal subjects and in cases of treated adrenal insufficiency and Cushing's syndrome. Journal of Clinical Endocrinology, 20, 253-265.

Endler, N. S., Hunt, J. McV., and Rosenstein, A. J. (1962). An S-R inventory of anxiousness. Psychological Monographs, 76, No. 536.

Eysenck, H. J., and Eysenck, S. B. G. (1964). Manual of the Eysenck Personality Inventory. University of London Press: London.

Gray, C. H., Baron, D. N., Brooks, R. V., and James, V. H. T, (1969). A critical appraisal of a method of estimating urinary 17-oxosteroids and total 17-oxogenic steroids. Lancet, 1, 124-127.

Jensen, A. R. (1958). The Maudsley Personality Inventory. Acta Psychologica (Amsterdam), 14, 314-325.

Jones, M. T., and Bridges, P. K. (1970). Effects of tetracosactrin on plasma corticosteroids in subjects of different body-build. Journal of Endocrinology, 48, 285-286.
Jones, M. T., Bridges, P. K., and Leak, D. (1968). Relationship between the cardiovascular and sympathetic responses to the psychological stress of an examination. Clinical Science, 35, 73-79.

Levi, L. (1969). Neuro-endocrinology of anxiety. In Studies of Anxiety, pp. 40-52. Edited by M. H. Lader. British Journal of Psychiatry Special Publication No. 3.

Martin, B. (1961). The assessment of anxiety by physiological behavioral measures. Psychological Bulletin, 58, 234-255.

Parnell, R. W. (1957). Physique and breakdown in young adults. British Medical Journal, 1, 1485-1490.

Parnell, R. W. (1958). Behaviour and Physique. Arnold: London.

Poe, R. O., Rose, R. M., and Mason, J. W. (1970). Multiple determinants of 17-hydroxycorticosteroid excretion in recruits during basic training. Psychosomatic Medicine, 32, 369-378.

Rees, L. (1960). Constitutional factors and abnormal behaviour. In Handbook of Abnormal Psychology, pp. 344-392. Edited by H. J. Eysenck. Pitman: London.

Rose, R. M., Poe, R. O., and Mason, J. W. (1968). Psychological state and body size as determinants of 17-OHCS excretion. Archives of Internal Medicine, 121, 406-413.

Segraves, R. T. (1970). Personality, body-build and adrenocortical activity. British Journal of Psychiatry, 117, 405-411.

Sheldon, W. H. (1942). The Varieties of Human Temperament. Harper: New York.

Tanner, J. M., Healy, M. J. R., Whitehouse, R. H., and Edgson, A. C. (1959). The relation of body-build to the excretion of 17 -ketosteroids and 17-ketogenic steroids in healthy young men. Journal of Endocrinology, 19, 87-101.

Taylor, J. A. (1953). A personality scale of manifest anxiety. Journal of Abnormal and Social Psychology, 48, 285-290.

Townsend, J., and James, V. H. T. (1968). A semi-automated fluorimetric procedure for the determination of plasma corticosteroids. Steroids, 11, 497-511.

Zenker, N., and Bernstein, D. E. (1958). The estimation of small amounts of corticosterone in rat plasma. Journal of Biological Chemistry, 231, 695-701. 